Die auf Anregung der Verlagsbuchhandlung im Anhang beigefügte Erläuterung einer Anzahl philosophischer Termini, welche sich fast ganz auf fremdsprachliche Ausdrücke beschränkt und die Bezeichnungen für die durchgehenden Richtungen bevorzugt, wurde nach Möglichkeit so eingerichtet, daß sie zugleich als Sachregister benutzt werden kann.

Jena, 23. Dezember 1885 .

\title{
Vorwort zur zweiten Auflage.
}

Von den Verănderungen und Zusätzen der neuen Auflage entfällt die Mehrzahl auf das erste und die beiden letzten Kapitel; von der allgemeinen Haltung der Darstellung abzugehen, fand ich keine Veranlassung. Mit aufrichtigem Danke gedenke ich der Anregungen, die mir sowohl die öffentlichen Besprechungen als auch privatim geäußerte Wünsche gewăhrten. Gelegentlich traf es sich, daß widersprechende Forderungen sich begegneten - so wurde auf der einen Seite Erweiterung, auf der anderen Kürzung der Abschnitte über den deutschen Idealismus, insbesondere über Hegel, befürwortet -; da war ich denn freilich außer stande, beiden zu entsprechen. Unter den Rezensionen war mir die von B. Erdmann im ersten Bande des Archivs für Geschichte der Philosophie, unter den brieflichen Verbesserungsvorschlägen die von H. Heußler von besonderem Werte. Da fremde Augen gewöhnlich schärfer sehen, so wäre es mir sehr willkommen, wenn mein Wunsch, diesen Grundriß immer nützlicher zu gestalten, auch ferner durch Ratschläge aus dem Leserkreise unterstützt würde. Sie werden, falls dem Buche die Gunst der Lehrer und der Lernenden erhalten bleibt, gewissenhaft berücksichtigt werden.

Für diejenigen, welche über zu große Fülle des Stoffes klagen, bemerke ich, daß sich durch Überspringung von Kap. I, 5 (Abschnitt $\mathrm{I}-3), 6,8,12,15$ und 16 leicht Abhilfe schaffen läBt.

Erlangen, Ir. Juni 1892. 